\title{
Methods to optimize myxobacterial fermentations using off-gas analysis
}

Stephan Hüttel ${ }^{1}$ and Rolf Müller ${ }^{1,2^{*}}$

\begin{abstract}
Background: The influence of carbon dioxide and oxygen on microbial secondary metabolite producers and the maintenance of these two parameters at optimal levels have been studied extensively. Nevertheless, most studies have focussed on their influence on specific product formation and condition optimization of established processes. Considerably less attention has been paid to the influence of reduced or elevated carbon dioxide and oxygen levels on the overall metabolite profiles of the investigated organisms. The synergistic action of both gases has garnered even less attention.

Results: We show that the composition of the gas phase is highly important for the production of different metabolites and present a simple approach that enables the maintenance of defined concentrations of both $\mathrm{O}_{2}$ and $\mathrm{CO}_{2}$ during bioprocesses over broad concentration ranges with a minimal instrumental setup by using endogenously produced $\mathrm{CO}_{2}$. The metabolite profiles of a myxobacterium belonging to the genus Chondromyces grown under various concentrations of $\mathrm{CO}_{2}$ and $\mathrm{O}_{2}$ showed considerable differences. Production of two unknown, highly cytotoxic compounds and one antimicrobial substance was found to increase depending on the gas composition. In addition, the observation of $\mathrm{CO}_{2}$ and $\mathrm{O}_{2}$ in the exhaust gas allowed optimization and control of production processes.

Conclusions: Myxobacteria are becoming increasingly important due to their potential for bioactive secondary metabolite production. Our studies show that the influence of different gas partial pressures should not be underestimated during screening processes for novel compounds and that our described method provides a simple tool to investigate this question.

Keywords: Myxobacteria, Secondary metabolites, Carbon dioxide, Oxygen, Process automation, Production optimization, Bioprocess, $\mathrm{OCQ}, \mathrm{COQ}, \mathrm{pO}_{2}, \mathrm{pCO}_{2}$
\end{abstract}

\section{Background}

The search for new antibiotics and other bioactive compounds has been intensified due to the development of multiple resistances in pathogenic bacteria and the lack of effective therapies against various - not only infectiousdiseases [1,2]. Despite well-developed techniques to create synthetic compound libraries, the chemical variety and complexity found in natural molecules are often inaccessible via synthesis and lead structures from Nature are still in demand [3]. Bacteria are well-documented sources for these

\footnotetext{
* Correspondence: rom@mx.uni-aarland.de
'Department of Pharmaceutical Biotechnology, Saarland University,

* Correspondence: rom@mx.uni-aarland.de
'Department of Pharmaceutical Biotechnology, Saarland University,

Saarbruecken, Germany

${ }^{2}$ Helmholtz-Institute for Pharmaceutical Research Saarland, Helmholtz Centre

for Infection Research and Pharmaceutical Biotechnology Saarland University, Saarbruecken, Germany
}

desired structures and, among microbes, myxobacteria are an important group, responsible for approximately $5 \%$ of the known bacterial compounds including molecules of considerable pharmaceutical interest [4,5]. Although thousands of different myxobacteria from diverse environmental sources have already been isolated and new species and even genera are still discovered [6], little is known about bioprocesses involving myxobacteria.

The myxobacterial genus Chondromyces appears to be a promising source for novel structures as several bioactive molecules, such as the chondramides and apicularens, have already been isolated and characterized $[7,8]$. To investigate the influence of the gaseous composition on myxobacterial growth and metabolic profile, SBCm007, a Chondromyces strain isolated in our laboratory, was chosen for its production of several uncharacterized compounds in addition to

\section{Biomed Central}

(c) 2012 Hüttel and Müller; licensee BioMed Central Ltd. This is an Open Access article distributed under the terms of the Creative Commons Attribution License (http://creativecommons.org/licenses/by/2.0), which permits unrestricted use, distribution, and reproduction in any medium, provided the original work is properly cited. 
the known chondramides A-D. A second strain, SBCm002, which produces the apicularens A and B and two crocapeptins derivatives, both molecule classes showed activity against hepatitis $C$ virus replication [9], was used to test if $\mathrm{O}_{2}$ and $\mathrm{CO}_{2}$ monitoring in the off-gas could help to optimize up- and downstream processing of myxobacterial fermentation processes.

The importance of a defined $\mathrm{pO}_{2}$ in the liquid phase to optimise production is documented by numerous examples of bioprocesses, mostly involving bacteria of the order Actinomycetales. In a Streptomyces clavuligerus culture, $100 \% \mathrm{pO}_{2}$ saturation maintained over the whole cultivation time resulted in cephamycin $\mathrm{C}$ production 2.4-fold higher than that obtained from an uncontrolled experiment, where $\mathrm{pO}_{2}$ dropped below $40 \%$. The authors showed that maintenance of $100 \%$ saturation was most critical during the exponential growth phase of the bacteria, where no production of cephamycin was observed. A drop from 100\% to 50\% after exponential growth delivered the same yields as $100 \%$ saturation over the whole cultivation time. Maintenance of $50 \%$ overall resulted in a four-fold lower yield, whereas biomass in all experiments was comparable [10]. In contrast, it was shown that high oxygen concentrations after the exponential growth phase of Amycolatopsis orientalis are crucial for vancomycin biosynthesis, although the biosynthetic machinery is present at high and low $\mathrm{pO}_{2}$ [11]. These effects can be explained by regulatory influence of $\mathrm{O}_{2}$ on gene expression levels and enzyme function, but another important factor is the presence of $\mathrm{O}_{2}$ as a substrate, which can e.g. influence the proportion of tetracycline, oxytetracycline and chlortetracycline yield in several Streptomyces strains cultivated at elevated pressure [12]. A myxobacterial example is the heterologous expression of epothilone in Myxococcus xanthus under 50\% and 0\% $\mathrm{pO}_{2}$ saturation, which had a significant influence on the proportion of epothilones A-D in the overall yield. An additional product, Epo506, was observed preferentially at higher $\mathrm{O}_{2}$ concentrations [13].

The evolution of $\mathrm{CO}_{2}$ under aerobic growth of microorganisms has been studied extensively and one major difference to $\mathrm{O}_{2}$ is that $\mathrm{CO}_{2}$ exists in the liquid phase as dissolved $\mathrm{CO}_{2}$ and carbonic acid $\left(\mathrm{H}_{2} \mathrm{CO}_{3}\right)$ in equilibrium with the $\mathrm{CO}_{2}$ in the gas phase and carbonic acid converts, dependent on the $\mathrm{pH}$ of the solute into bicarbonate $\left(\mathrm{HCO}_{3}^{-}\right)$and the carbonate ion $\left(\mathrm{CO}_{3}^{2-}\right)$, as shown in Figure 1. This complicates the investigation of the regulatory functions of $\mathrm{CO}_{2}$ itself because it is difficult to estimate which species is responsible for an effect. Particularly around $\mathrm{pH} 7$, where myxobacterial fermentation usually occurs, an increase of both $\mathrm{pH}$ dependant species is observed. Possible effects on cells, enzymes, and product formation are reviewed extensively in $[13,14]$ and, though

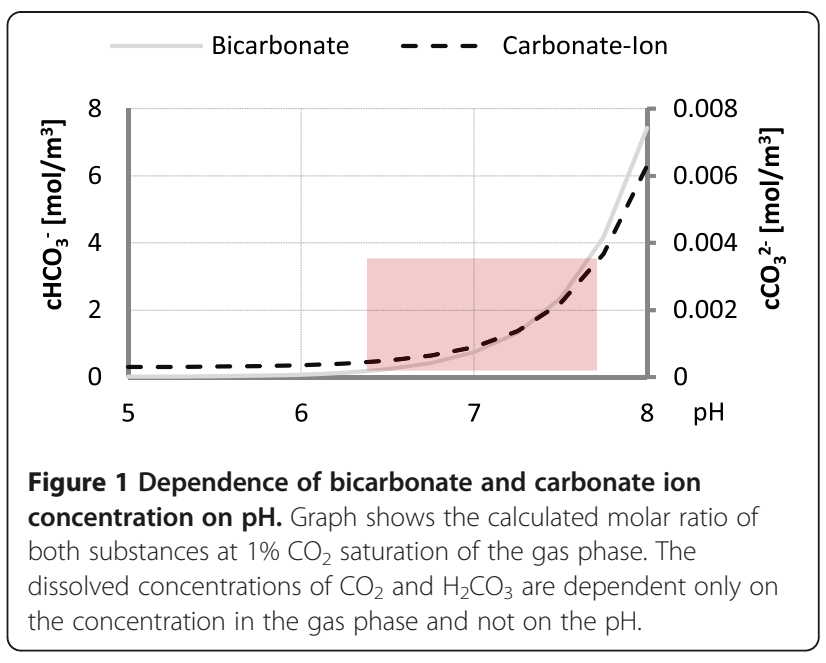

it seems that higher concentrations correlate mostly with inhibiting effects under aerobic growth, there is evidence that low concentrations are at least somewhat beneficial and may be required for growth and production. In contrast, there have been reports that production of the antibacterial compound amylovorin L by Lactobacillus amylovorus is optimal under anaerobic conditions and high $\mathrm{CO}_{2}$ tensions. Similar findings are valid for induction of the toxic shock syndrome toxin 1 in Staphylococcus aureus $\mathrm{MN} 8$, where $\mathrm{CO}_{2}$ concentrations of about $7 \%$ and $\mathrm{O}_{2}$ concentrations of about $21 \%$ in the gas phase were required for optimal production.

Taken together, it becomes evident that, although much is known about $\mathrm{O}_{2}$ requirements, biosynthetic routes, and inhibitory or stimulatory effects of $\mathrm{CO}_{2}$, it is impossible to predict the influence of reduced or increased concentrations of these two gases on secondary metabolite production, particularly of new and unknown metabolites. Furthermore, the lack of literature where the effects of both parameters are observed in concert shows that there is an enormous potential for process optimization. In this study, we tested the influence of gas composition on the secondary metabolite profile of strain SBCm007. Our findings indicated the importance of a controlled gaseous environment. To address this issue, we developed a technique which allows, with minimal instrumental setup, the maintenance of both gases at defined concentrations during cultivation by using off-gas analysis and dissolved $\mathrm{O}_{2}$ as control parameters. Our studies further reveal that the introduction of two new parameters COQ and OCQ - both based on off-gas analysis-gives us a very sensitive tool that may be useful in process monitoring and automation. We demonstrate their use in condition optimization and the control of repeated batch cultivation with respect to better production and simplified downstream processing with promising results. 


\section{Results and discussion}

Influence of $\mathrm{O}_{2}$ and $\mathrm{CO}_{2}$ tension on secondary metabolite production

This test was performed with a novel Chondromyces strain $\mathrm{SBCm007}$ isolated in our laboratory. Due to unavoidable concentration differences in autogenously produced $\mathrm{CO}_{2}$ resulting from problems with the typical coagulative growth and thereby associated irreproducibility of inoculum density, a repeated batch setup was used when repetitive pattern state conditions were reached, as described in Materials and Methods. Thereby, the same culture could be used for all tests. The conditions for the tests were chosen from preliminary trial runs carried out between three to ten times which showed an effect on secondary metabolite production. The tests were performed in the order listed in Table 1, along with standard conditions before and after the test cultivations to ensure that no bigger deviations occur caused by the changed conditions or adaptive mutations. To rule out influences caused by shearing stress, the stirring rate was kept constant and $\mathrm{pO}_{2}$ maintained by changing the flow rate.

To compare the productivity under different conditions, the production of twelve target compounds (TC), including the highly cytotoxic chondramides A and B, was examined. These TCs were chosen when the preliminary tests showed reproducible influences caused by changes in gaseous composition. Figure 2 shows an example of an overlay of two base peak chromatograms measured in positive mode which were used for yield calculation. The twelve TCs are labelled A to J according to their retention time and marked when present in the extract. The overall productivity was calculated as described in Materials and Methods using sulfadimethoxine as an internal standard (see Figure 2) and the results are shown in Figure 3 as the relative productivity in comparison to the other conditions. The twelve compounds are characterized as low, medium, or highly abundant to enhance the clarity of the graph. The grey shaded box indicates yields obtained with a new method discussed in the next section and will not be considered here. The red shaded box marks the 'standard' conditions. The calculations clearly show the best production conditions for chondramides $\mathrm{A}$ and $\mathrm{B}$ are at low oxygen tension, as with compounds $\mathrm{F}$ and $\mathrm{G}$. Production of compounds $\mathrm{C}$ and $\mathrm{J}$ seem to profit from low $\mathrm{O}_{2}$ and $\mathrm{CO}_{2}$ tension. Compounds $\mathrm{A}$ and $\mathrm{E}$ are best produced under high $\mathrm{O}_{2}$ and $\mathrm{CO}_{2}$ tension, whereas production of $\mathrm{B}, \mathrm{D}, \mathrm{H}$ and $\mathrm{I}$ seem to require only high $\mathrm{O}_{2}$ concentrations. Interestingly, the 'standard' conditions are suboptimal for production of all of the TCs.

Preliminary tests show highly cytotoxic activity for compounds $\mathrm{F}$ and $\mathrm{G}$ ( $\mathrm{IC}_{50}$ about $28.6 \mathrm{nM}$ and $44.2 \mathrm{nM}$ on HCT-116 cells, data not shown) and weak cytotoxic and antibacterial activity in the micro-molar range for compound $\mathrm{H}$ (data not shown). For compound I, the increase in productivity under the tested conditions is not very high as shown in Figure 3. However, even a $20 \%$ improvement of overall yield in the low abundance group can uncover undetected activity or enable the production of sufficient amounts for chemical characterisation of a substance. For some compounds, very specific conditions seem to be required, as for $\mathrm{C}, \mathrm{E}$ and J, which excludes the possibility for a single condition where all compounds can be produced in sufficient amounts. Furthermore, the application of standard cultivations usually only includes the control of $\mathrm{pO}_{2}$ and neglects $\mathrm{CO}_{2}$ concentration. Using the standard methods applied here, it was impossible to establish $100 \%$ reproducible conditions and the need for a method to maintain both gases at defined concentrations is obvious.

\section{Development of a method for maintenance of $\mathrm{O}_{2}$ and $\mathrm{CO}_{2}$ tension}

The influence of gas phase composition on the secondary metabolite profile shows the importance of maintenance of both gases inside the bioreactor. The lack of simple methods to achieve this led to the investigation of the dependency of $\mathrm{k}_{\mathrm{l}} \mathrm{a}$ on stirring speed and flow rate.

Table 1 List of different test runs, the according gaseous composition and the method used to maintain $\mathrm{pO}_{2}{ }^{*}$

\begin{tabular}{|c|c|c|c|c|c|}
\hline $\begin{array}{l}\text { Low } \mathrm{O}_{2} \\
\text { Moderate } \mathrm{CO}_{2}\end{array}$ & $\begin{array}{l}\text { Low } \mathrm{O}_{2} \\
\text { No } \mathrm{CO}_{2}\end{array}$ & $\begin{array}{l}\text { Moderate } \mathrm{O}_{2} \\
\text { Moderate } \mathrm{CO}_{2}\end{array}$ & $\begin{array}{l}\text { High } \mathrm{O}_{2} \\
\text { High } \mathrm{CO}_{2}\end{array}$ & $\begin{array}{l}\text { High } \mathrm{O}_{2} \\
\mathrm{No} \mathrm{CO}_{2}\end{array}$ & $\begin{array}{l}\text { Moderate } \mathrm{O}_{2} \\
\text { High } \mathrm{CO}_{2}\end{array}$ \\
\hline $\mathrm{pO}_{2} 5 \%$ & $\mathrm{pO}_{2} 5 \%$ & $\mathrm{pO}_{2} 20 \%$ & $\mathrm{pO}_{2} 55 \%$ & $\mathrm{pO}_{2} 55 \%$ & $\mathrm{pO}_{2} 20 \%$ \\
\hline $\mathrm{CO}_{2}-0.3-0.6 \%$ & $\mathrm{CO}_{2}<0.1 \%$ & $\mathrm{CO}_{2}-0.2-0.3 \%$ & $\mathrm{CO}_{2} 1.0-2.0 \%$ & $\mathrm{CO}_{2}<0.1 \%$ & $\mathrm{CO}_{2} 1.8 \%$ \\
\hline $\begin{array}{l}\text { Shearing stress } \\
\text { comparable to } \\
\text { standard conditions }\end{array}$ & $\begin{array}{l}\text { Shearing stress comparable to } \\
\text { standard conditions }\end{array}$ & Standard conditions & $\begin{array}{l}\text { Shearing stress } \\
\text { comparable to } \\
\text { standard conditions }\end{array}$ & $\begin{array}{l}\text { Shearing stress } \\
\text { comparable to } \\
\text { standard conditions }\end{array}$ & $\begin{array}{l}\text { New Method: } \\
\text { Shearing stress } \\
\text { dependent on stirrer } \\
\text { speed }\end{array}$ \\
\hline $\begin{array}{l}\text { Gaseous composition } \\
\text { and } \mathrm{pO}_{2} \text { regulated } \\
\text { by aeration with } \\
\text { ambient air }\end{array}$ & $\begin{array}{l}\text { Gaseous composition and } \mathrm{pO}_{2} \\
\text { regulated by aeration with } \\
\text { ambient air stripping of } \mathrm{CO}_{2} \\
\text { with nitrogen gas }\end{array}$ & $\begin{array}{l}\text { Gaseous composition } \\
\text { and } \mathrm{pO} 2 \text { regulated } \\
\text { by aeration with } \\
\text { ambient air }\end{array}$ & $\begin{array}{l}\text { Gaseous } \\
\text { composition and } \\
\mathrm{pO}_{2} \text { regulated by } \\
\text { aeration with pure } \\
\mathrm{O}_{2}\end{array}$ & $\begin{array}{l}\text { Gaseous composition } \\
\text { and } \mathrm{pO}_{2} \text { regulated } \\
\text { by aeration with } \\
\text { ambient air }\end{array}$ & $\begin{array}{l}\text { Gaseous composition } \\
\text { and } \mathrm{pO} 2 \text { regulated } \\
\text { by aeration with } \\
\text { ambient air }\end{array}$ \\
\hline
\end{tabular}

*Trials were carried out in the presented order. Before and after the tests one standard run was carried out to ensure that no significant deviations are caused by the test runs. 


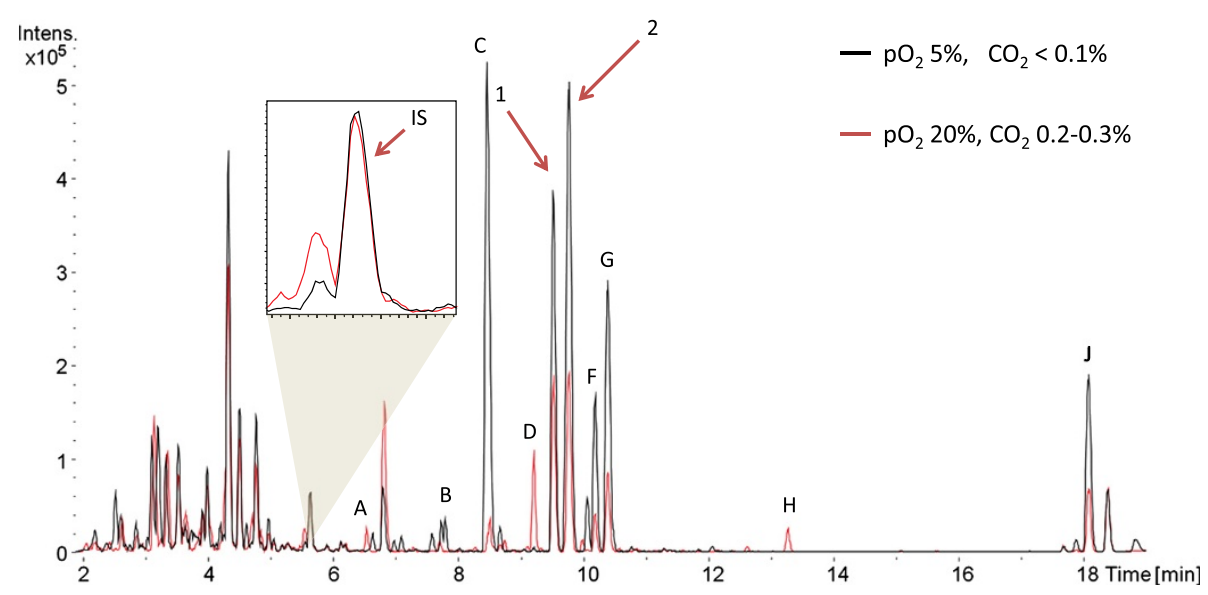

Figure 2 Overlay of MS chromatograms of two extracts from a Chondromyces strain. Overlay of two base peak chromatograms measured in positive ionisation mode. Peaks corresponding to a compound mentioned in the text are marked by the corresponding letter. 1 indicates chondramide A and 2, chondramide B. The small window enlarges the overlay of the peak corresponding to the internal standard (IS).

Figure 4 shows a $3 \mathrm{D}$ plot of $\mathrm{k}_{\mathrm{l}} \mathrm{a}$ values with respect to these two parameters as measured in a bioreactor with water filling without any microorganism. It is obvious that, at low stirring rates, the increase in $\mathrm{k}_{\mathrm{l}} \mathrm{a}$ at elevated flow rates has a linear dependency. At higher stirring rates, a sharp increase from zero flow to moderate flow rates occurs, followed by a linear increase. This effect can be explained by the following equations, which are generally used to calculate the oxygen transfer rate (OTR $\left.\left[\mathrm{mg} / \mathrm{l}^{*} \mathrm{~s}\right]\right)$ :

$$
O T R=k_{l} a\left(C_{O_{2}}^{*}-C_{l}\right)
$$

where $\mathrm{C}_{\mathrm{O} 2}^{*}[\mathrm{mg} / \mathrm{l}]$ is the maximum dissolved concentration of $\mathrm{O}_{2}$ at the actual conditions according to Henry's law and $\mathrm{C}_{1}[\mathrm{mg} / \mathrm{l}]$ is the actual concentration of $\mathrm{O}_{2}$ dissolved in the liquid. $\mathrm{k}_{1} \mathrm{a}[1 / \mathrm{s}]$ is the mass or oxygen transfer coefficient per unit volume and can be expressed as:

$$
k_{l} a=k_{l} \frac{A}{V}
$$

where $k_{1}[\mathrm{~m} / \mathrm{s}]$ is the mass transfer coefficient, $A\left[\mathrm{~m}^{2}\right]$ is the interface area between gas and liquid phase in the bioreactor and $\mathrm{V}\left[\mathrm{m}^{3}\right]$ is the liquid volume. This shows that there are two driving forces for mass transfer: the concentration difference (see Eq. 1) and the $k_{1}$ a value and its associated gas-liquid interface. Increasing $\mathrm{k}_{\mathrm{l}} \mathrm{a}$ means increasing the interface area between liquid and gas phase (see Eq. 2). The latter can be achieved by increasing the flow rate, which results in a higher number of bubbles with approximately the same diameter and surface area, resulting in the observed linear increase of $k_{l} a$ with increasing flow rates. A higher mass transfer rate in common bioreactors can also be achieved by increasing the stirring rate, leading to greater dispersion of the bubbles and thereby to an exponential increase of bubble surface area. This explains the exponential increase of $k_{1} a$ in the 3D plot of Figure 4 when the stirring rate is increased.

Furthermore, the influence of $\mathrm{O}_{2}$ in the headspace volume on $\mathrm{k}_{1} \mathrm{a}$ with respect to stirring speed was investigated. To examine this, the headspace volume was exchanged permanently and no air was sparged through the liquid phase. Figure 4 shows that the effect is relatively low at $150 \mathrm{rpm}$ but the transfer rates obtained through headspace exchange at $500 \mathrm{rpm}$ were about $10 \%$ of the values obtained by sparging air through the liquid phase. This is due to greater dispersion of air from the surface to the liquid phase at higher stirring rates. The contour plot in Figure 4 illustrates that similar $\mathrm{k}_{1}$ a values can be reached with a flow of $1.5 \mathrm{l} / \mathrm{min}$ and $150 \mathrm{rpm}$ stirring rate or $0.1 \mathrm{l} / \mathrm{min}$ and $500 \mathrm{rpm}$, which can be partially traced back to headspace effects.

These combined characteristics of sparged air and head space effects can be used to control accumulation of $\mathrm{CO}_{2}$ in the bioreactor by setting $\mathrm{pO}_{2}$ under the control of flow rate and $\mathrm{CO}_{2}$ concentration in the off-gas under the control of the stirring rate. In both cases, a negative control deviation should lead to upregulation of the actuating variable and a positive deviation, to downregulation (The setting of the underlying PI control is listed in the Methods section). $\mathrm{A} \mathrm{CO}_{2}$ concentration below the set point, for example, would lead to an increase in stirring rate, thereby increasing $\mathrm{k}_{\mathrm{l}} \mathrm{a}$ and reducing the required flow rate. A decreased flow rate results in a reduced exchange of the headspace volume, thereby allowing $\mathrm{CO}_{2}$ accumulation until the set point is reached and the actuating variables remain constant. $\mathrm{pCO}_{2}$ in the liquid phase is assumed to be in equilibrium to the gas phase $\mathrm{CO}_{2}$ according to Henry's law in an ideally mixed tank because the limiting step in gas exchange is the diffusion of 


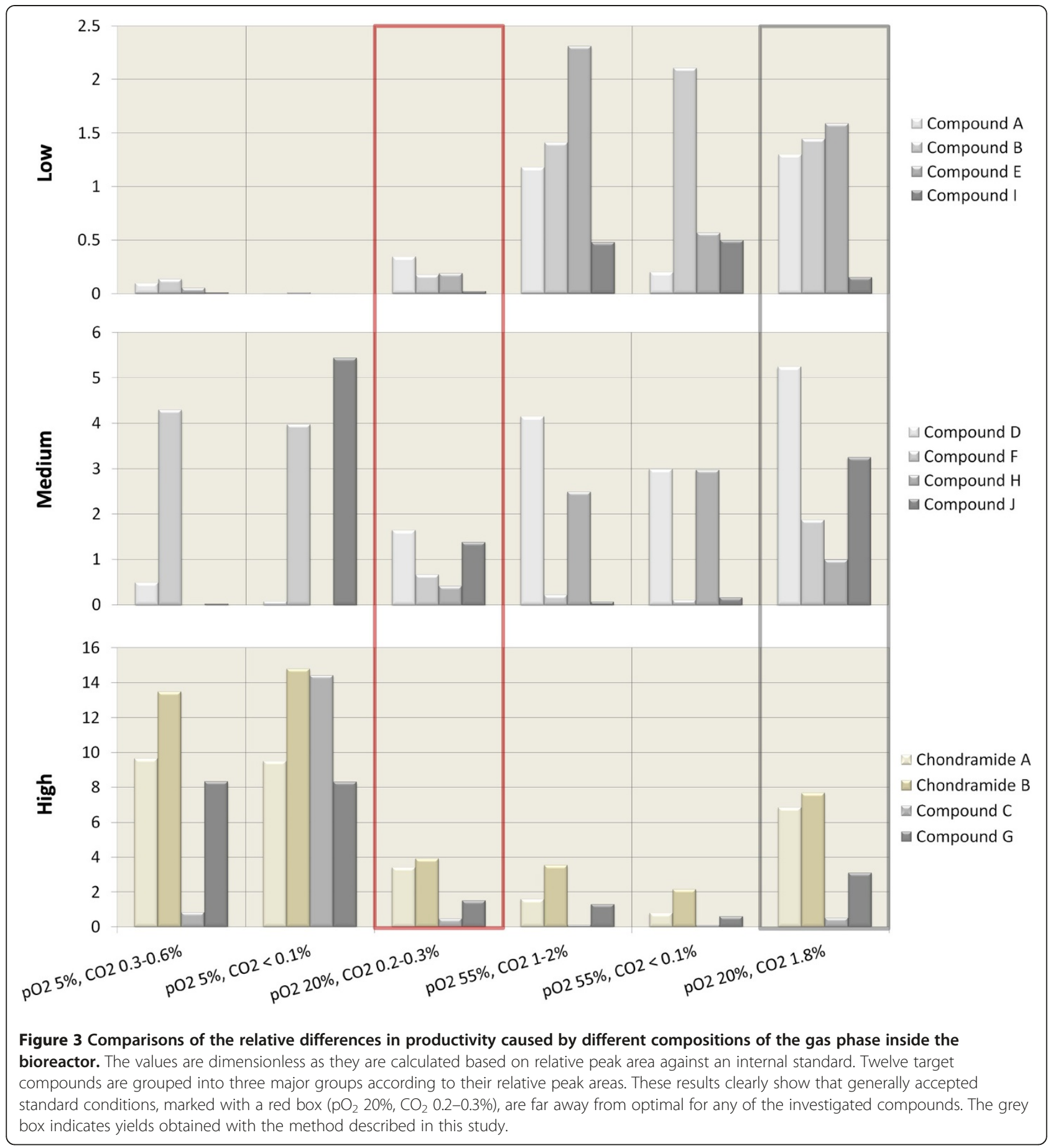

$\mathrm{CO}_{2}$ in the liquid phase. Results from literature confirm this, at least for non-viscous culture broths where gas diffusion is not hindered $[15,16]$.

In this study Saccharomyces cerevisiae was used for all initial trials because test runs could be performed after 1-2 days whereas preparation of myxobacterial starter cultures took usually between five to seven weeks. The underlying principles of the effects relevant for this study could be investigated regardless whether the respiratory active organism was of myxobacterial or fungal origin, results could be transferred to myxobacterial cultivations. Our initial testing showed that the influence of shear stress on the microbes must be considered because increased $\mathrm{CO}_{2}$ levels can only be achieved through higher stirring rates. A test cultivation with our model organism revealed that $\mathrm{CO}_{2}$ levels between $0.5-8.0 \%$ can 


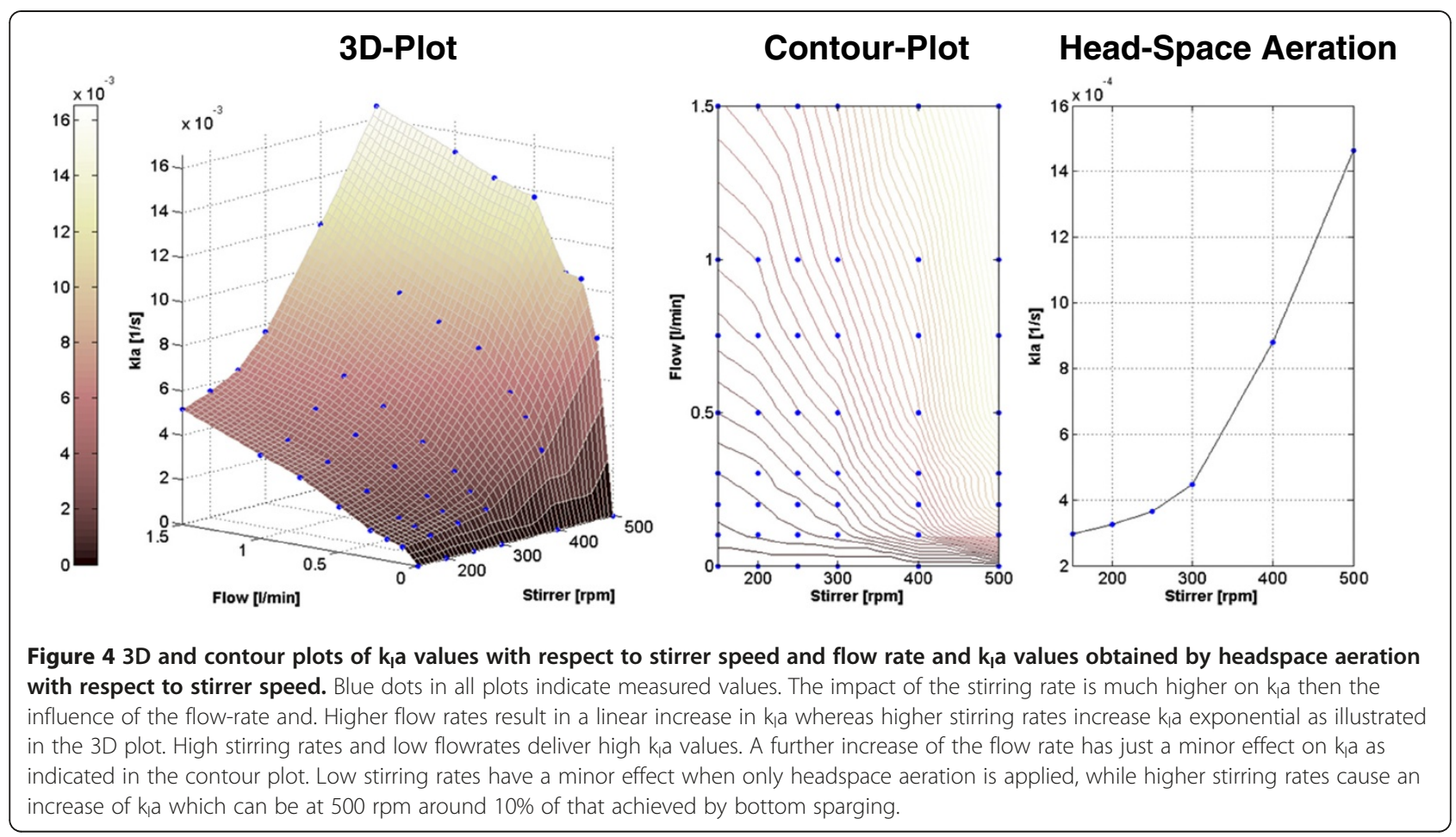

be achieved with stirring rates between $200-800 \mathrm{rpm}$ in minimal media with endogenously produced $\mathrm{CO}_{2}$ and ambient air when $\mathrm{pO}_{2}$ is set to $20 \%$ (data not shown). If higher $\mathrm{CO}_{2}$ concentrations are required, the use of pure $\mathrm{O}_{2}$ gas can reduce the required flow rate further and increase accumulation of $\mathrm{CO}_{2}$. To reduce the initial loading phase when endogenously produced $\mathrm{CO}_{2}$ is used an external $\mathrm{CO}_{2}$ loading pulse is conceivable. For very low $\mathrm{CO}_{2}$ concentrations at low $\mathrm{pO}_{2}$, the additional stripping of $\mathrm{CO}_{2}$ with nitrogen gas is required (see Figure 3, compounds $\mathrm{C}$ and J). Shang and co-workers presented the autogenous $\mathrm{CO}_{2}$ method' where they increased $\mathrm{CO}_{2}$ concentration by exchange of air gassing with pure oxygen and reducing thereby the flow rate [17]. This method allows only variations of $\mathrm{CO}_{2}$ but no real control. Using the proposed method allows the operator a tight control and also defined changes and growth phase dependent adaption of $\mathrm{CO}_{2}$ concentration during fermentations (data not shown).

Figure 5 shows a fermentation graph of a repeated batch cultivation performed in triplicate with strain $\mathrm{SBCm} 007$. $\mathrm{pO}_{2}$ was set at $20 \%$ in all cases and $\mathrm{CO}_{2}$ concentration at $0.3,0.6$ and $1.4 \%$. The results clearly demonstrate the applicability of this technique. The last column in Figure 3 shows yields obtained with that method from a cultivation of $\mathrm{SBCm} 007$ at $20 \% \mathrm{pO}_{2}$ saturation and $1.8 \% \mathrm{CO}_{2}$ concentration in the off-gas compared with results of the above section. For compounds $\mathrm{A}, \mathrm{B}$ and $\mathrm{D}$, production is best under these conditions. For all compounds, production is superior to standard conditions indicating the potential for optimisation.
OCQ and COQ as new parameters for process automation

As shown in the previous section, the gas composition of the off-gas is a direct result of respiratory activity, flow rate, and power entry into the media. A closer look at the influence of $\mathrm{CO}_{2}$ and $\mathrm{O}_{2}$ revealed that both gases deliver very specific growth phase- and nutrient-dependent curves which can be measured via off-gas analysis based on infrared measurement for $\mathrm{CO}_{2}$ and zirconium dioxide membrane potential for $\mathrm{O}_{2}$. Calculated values like OUR, carbon dioxide evolution rate (CER), and respiratory quotient RQ were not sufficiently sensitive and too susceptible to perturbations for use as monitoring or automation signals due to the weak respiratory activity of the investigated organisms. This leads to relatively small differences of $\mathrm{CO}_{2}$ and $\mathrm{O}_{2}$ concentrations in comparison to fresh air. This fact makes calculation of useful CER/OUR values impossible due to the experimentally observed "noise" (data not shown). Therefore other possible readouts were investigated.

We found that division of off-gas $\mathrm{O}_{2}$ by off-gas $\mathrm{CO}_{2}$ concentration $\left(\mathrm{O}_{2}-\mathrm{CO}_{2}\right.$-Quotient or OCQ) and vice versa (COQ) might be valuable tools for these purposes. The fact that $\mathrm{O}_{2}$ and $\mathrm{CO}_{2}$ concentration in the off-gas are inversely related with respect to biological activity 'amplifies' the calculated signals. This means that higher biological activity reduces $\mathrm{O}_{2}$ and increases $\mathrm{CO}_{2}$ in the off gas resulting in a calculated parameter where influences of both gases are combined in one value increasing sensitivity in comparison to OUR and CER where only one factor is used for calculation. Further amplification comes from the effects described in the above section. For example maintenance 


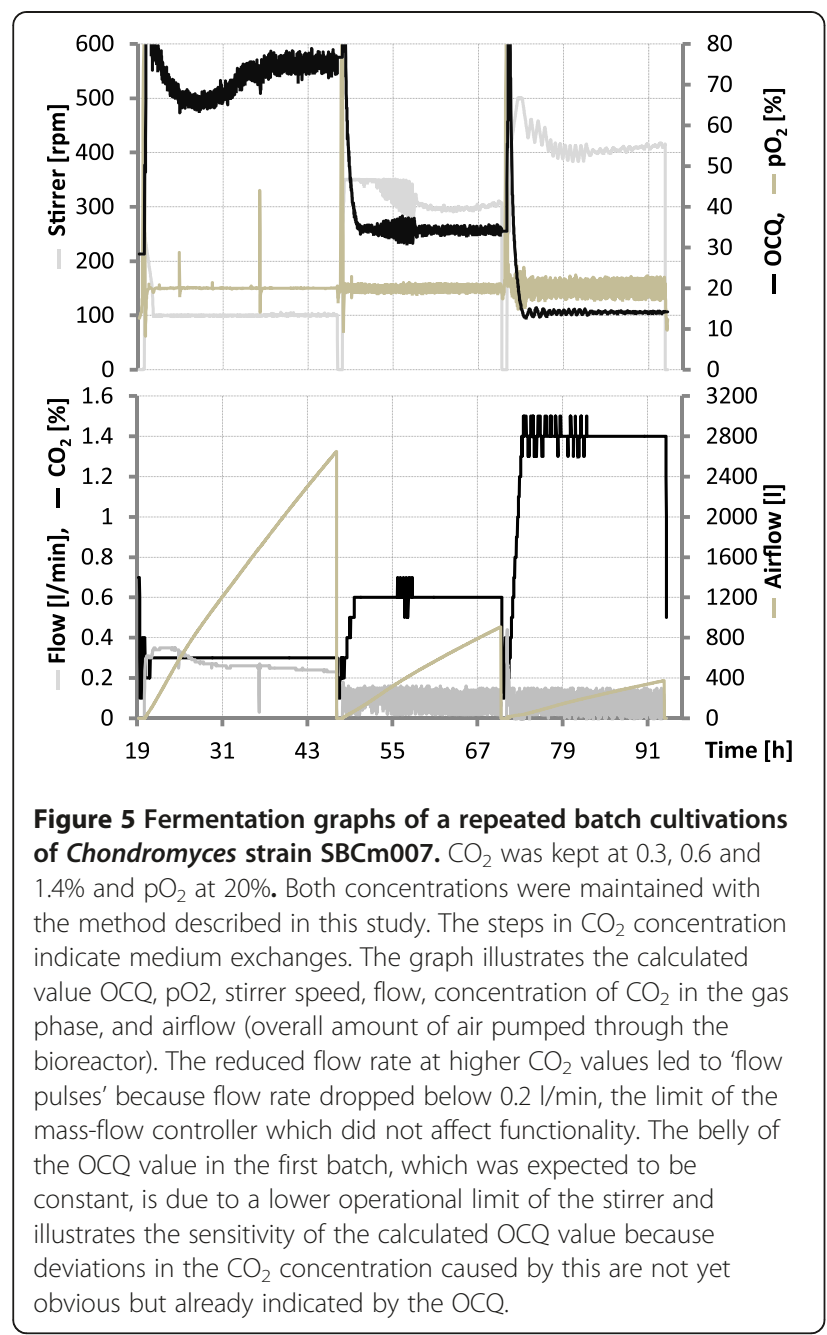

via flow rate leads to high OCQ values at high biological activity because $\mathrm{CO}_{2}$ is constantly blown out and mass transfer of $\mathrm{O}_{2}$ from air into media is not comparable to mass transfer achieved with increasing stirring rates leading to high $\mathrm{O}_{2}$ concentrations in the off gas. Vice versa at low respiratory activity OCQ reaches low values because the flow rate decreases and the mass transfer from the headspace becomes more important leading to accumulation of $\mathrm{CO}_{2}$ and reduction of $\mathrm{O}_{2}$ in the off gas. The resulting OCQ curve in a batch process with $\mathrm{pO}_{2}$ maintenance via flow rate starts usually at low values, increases when the cells reach the exponential growth phase and drops again when the respiratory activity decreases due to nutrient depletion. The corresponding COQ curve behaves inversely as it represents the reciprocal value of OCQ. The shape of these curves can be influenced by the initial setting of the stirring rate and must be tested beforehand. When $\mathrm{pO}_{2}$ is maintained via stirring rate the resulting OCQ curve starts at high values due to the constant blowing out of $\mathrm{CO}_{2}$ at the beginning of the cultivation where only low respiratory activity takes place. Once cells reach the exponential growth phase $\mathrm{CO}_{2}$ is produced and $\mathrm{O}_{2}$ concentration in the exhaust gas reduced by mass transfer from air into liquid phase resulting in a drop of the OCQ value. At the end of the cultivation OCQ rises again. The overall shape here is dependent on the initial flow rate and must also be tested beforehand. Figure 6 shows the calculated dependency of OCQ and COQ when ambient air is used as $\mathrm{O}_{2}$ source and the cultivated organism has a RQ of 1 meaning production of one portion $\mathrm{CO}_{2}$ removes the same portion of $\mathrm{O}_{2}$ from the exhaust gas. This calculation indicates best sensitivity of OCQ at lower $\mathrm{CO}_{2}$ concentrations and vice versa best sensitivity at higher $\mathrm{CO}_{2}$ concentrations for COQ. The setting of the stirring and flow rate allows moving conditions either to the right or the left side. This finding makes especially OCQ a valuable tool for respiratory weakly active organisms like myxobacteria. After averaging the signals, the measurement noise is filtered out and relatively smooth signals are obtained. Figure 7 illustrates the time-dependent development of both parameters during a batch cultivation of our test organism Saccharomyces cerevisiae were $\mathrm{pO}_{2}$ is maintained via stirring rate. A direct comparison of these parameters and CER/OUR is not possible since the latter ones are independent from cultivation conditions which is not the case for OCQ/COQ. Both parameters are dependent on the applied conditions and react very sensitive in their specific range on changes of stirring speed, flow rate and respiratory activity. The curves obtained are typical and highly reproducible for cultivations performed under the same conditions. The reproducibility of these curves was used to automate a repeated batch cultivation of Chondromyces strain

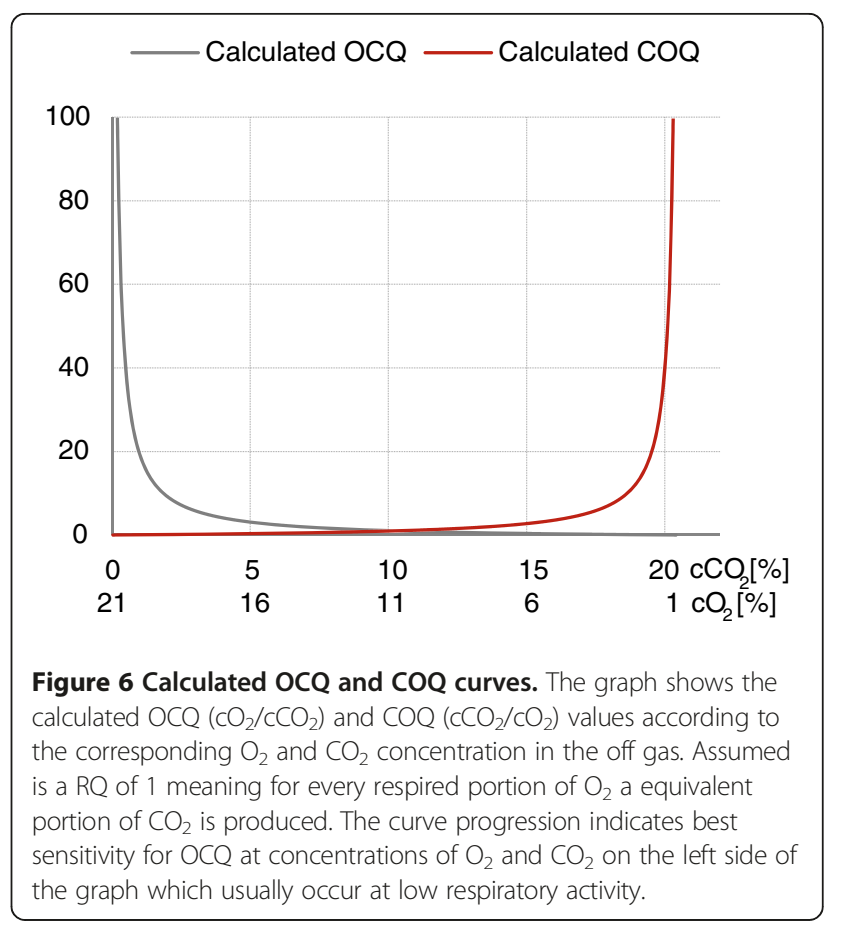




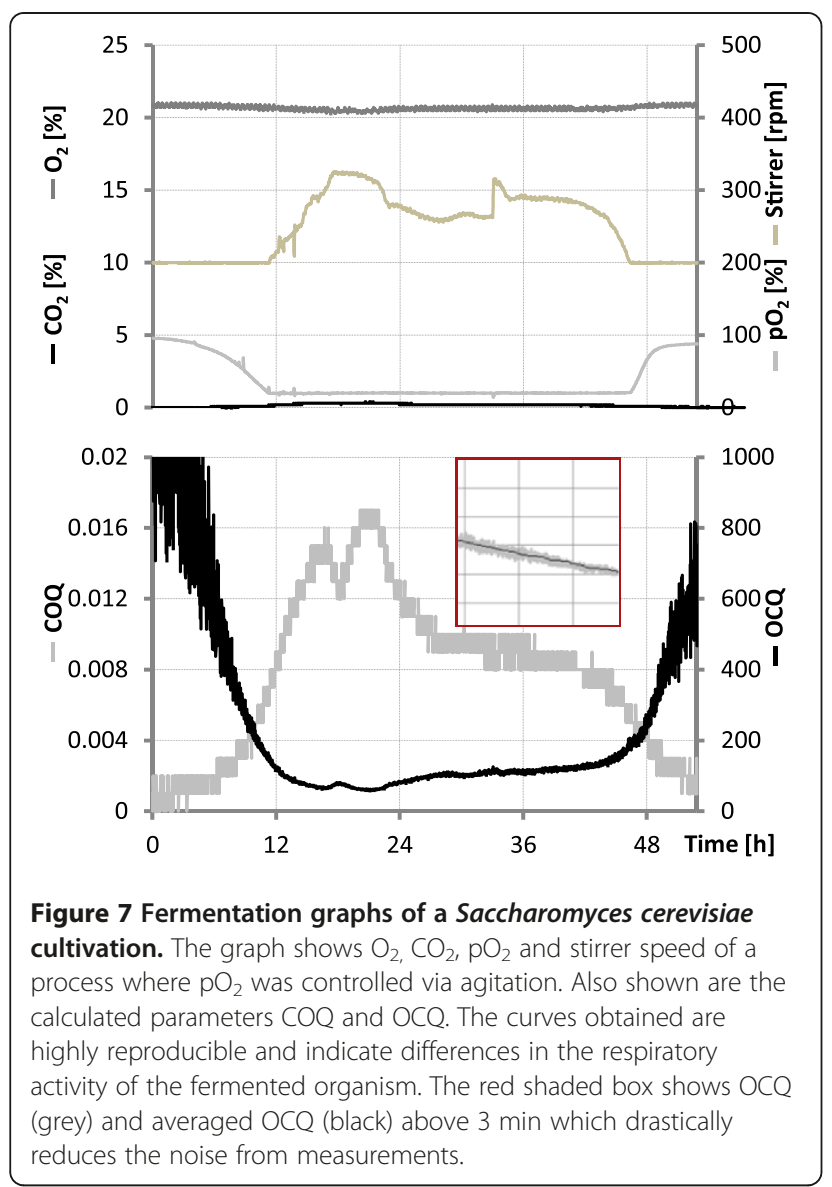

$\mathrm{SBCm} 002$ once the culture reached repeated pattern state. The $\mathrm{pO}_{2}$ in this cultivation was maintained via flow rate. The resulting OCQ curve (see. Figure 8) is slightly different from those described earlier in the text as typical for this type of $\mathrm{pO}_{2}$ maintenance. This is due to the relative high amount of biomass at the beginning of a cycle in comparison to usual batch cultivations. This leads to a skipping of the lag phase resulting in a steep increase of OCQ after media exchange and then a slow decrease when nutrients are depleted. The time of media exchange was set under control of a lower threshold of OCQ which was the actual value when the time point of manual media exchange based on experience of the experimentator was reached. Then the cultivation was carried out under full automation using the control software of the bioreactor with approximately 1.5 media exchanges per day and subsequent capturing of metabolites on an adsorber resin (Amberlite XAD16) until the process was stopped after 22 days. Figure 8 shows an excerpt of the OCQ curve, where a lower threshold was used to trigger media exchange.

One advantage of this method is that it required just one cultivation cycle to use the experience of the microbiologist and incorporate it into an automation script running

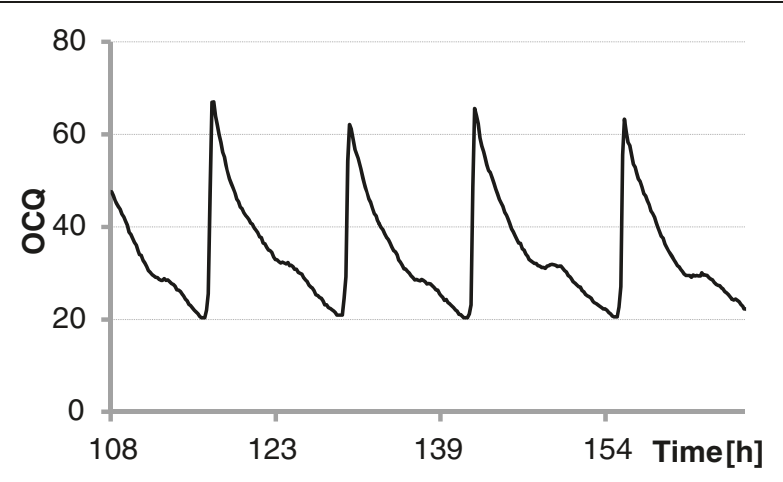

Figure 8 OCQ of a repeated batch cultivation of Chondromyces strain $\mathrm{SBCm002}$. The $\mathrm{pO}_{2}$ was maintained via aeration and the stirring rate was kept constant, resulting in an increase of $\mathrm{CO}_{2}$ and decrease of $\mathrm{O}_{2}$ in the off-gas once respiratory activity decreased. The resulting OCQ curves are highly specific and a lower threshold of this value was used to trigger automated media exchange and metabolite capturing. The culture was maintained for 22 days with approximately 1.5 media replacements daily.

on the control system of the bioreactor by simply using a lower threshold of the OCQ value to trigger the media exchange. By using this very simple automation procedure it was possible to use the potential of the producing cells for more than 20 days before the process was stopped manually. Batch processes in comparison are usually finished in less then one week and fed batch processes in less then two weeks due to self intoxication of the cells as a side effect of the complex cultivation medium. To compare the productivity of this process with a common batch cultivation the supernatant of one cultivation cycle was captured separately and matched with a comparable batch process with cultivation in presence of the adsorber resin. XAD16 is usually added directly to the culture to prevent degradation of secondary metabolites during the cultivation by adsorbing them to the resin. This comparison revealed that the undesired binding of media compounds to the resin is drastically reduced in repeated batch mode. This so called resin fouling is usually a major problem in downstream processing of material produced with conventional cultivation techniques due to reduced binding capacity of the resin and purification problems. Figure 9 shows three base peak chromatograms measured in positive ionisation mode of a medium extract, an extract of the batch cultivation with direct addition of XAD and an extract of a single cycle of the repeated batch with subsequent capturing. The reduced binding of media compounds is shown with the shaded box. Figure 10 shows a comparison of the overall productivity of apicularen A and two crocapeptin derivatives from these cultivations. Both substance classes attracted attention in an anti $\mathrm{HCV}$ screening [9]. The yield of apicularen A is reduced in the repeated batch cultivation whereas the yields of the 


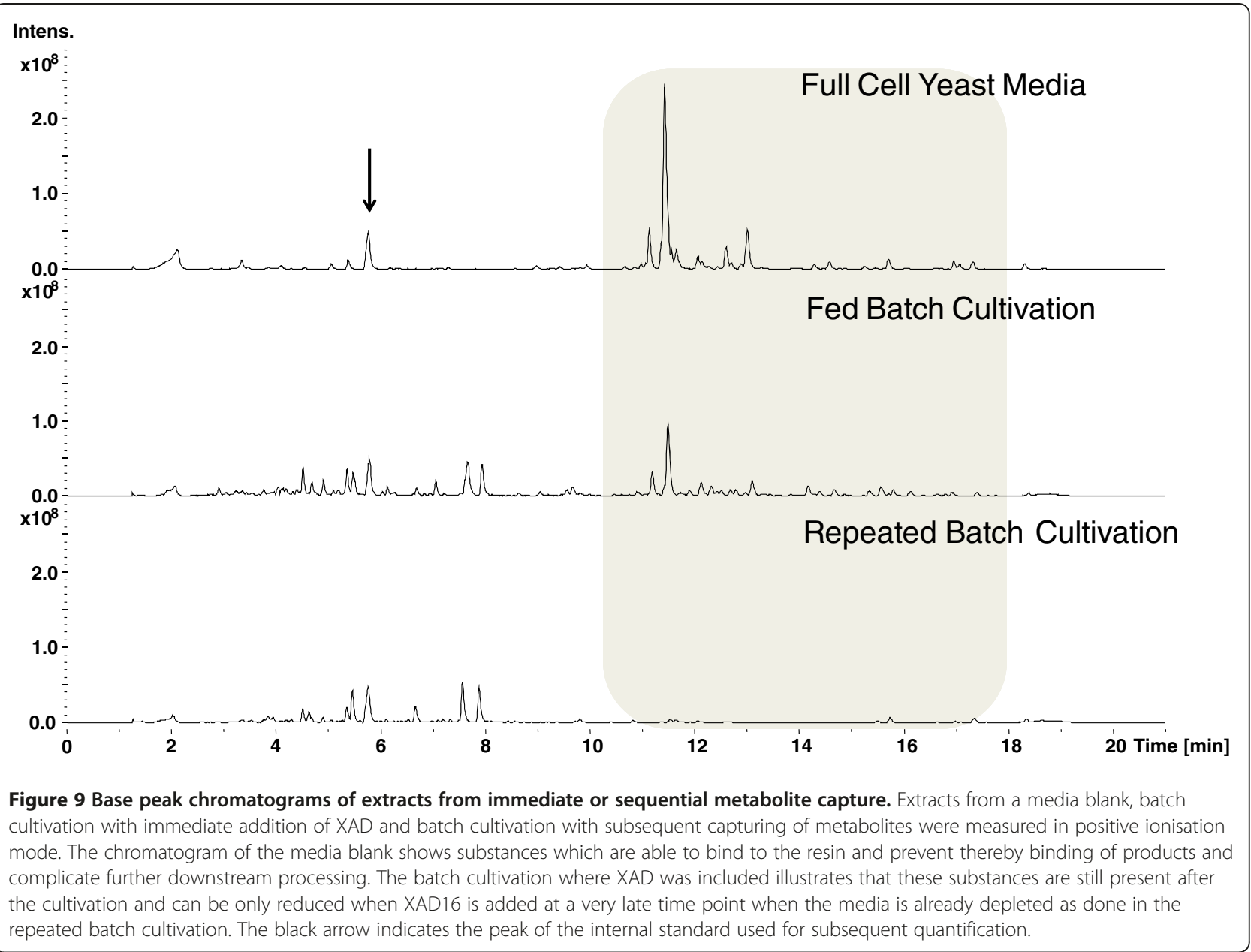

crocapeptins are comparable or even better than with addition of XAD, a phenomenon observed for several other compounds also (data not shown). This indicates a drawback of the method when degradation sensitive compounds are targeted but can be of advantage when production of metabolites is upregulated when these molecules are not captured directly.

These findings indicate that production must be optimized for every single compound, but in cases where compounds are neither toxic nor sensitive to degradation, OCQ can be a valuable tool for process automation and optimisation and to prolong thereby the productive time of these difficult to handle organisms. Due to its sensitivity, it can be probably used for control and maintenance of steady-state conditions e. $\mathrm{g}$. as actuating variable for the dilution rate in perfusion processes or as feed control in fed batch processes, preliminary results are very promising (data not shown). Figure 5 illustrates that OCQ remains constant once steady state conditions are reached-in this case, the balance of $\mathrm{CO}_{2}$ to $\mathrm{O}_{2}$. The responsiveness of OCQ becomes clear in the first batch round, as shown in the graph. Due to a lower threshold, the stirring rate could not be decreased further to maintain $\mathrm{pCO}_{2}$ with the method mentioned above. Although effects on $\mathrm{CO}_{2}$ concentration are rather small, the OCQ illustrates this clearly by dropping below the expected steady state value, demonstrating the sensitivity of this method. Once the growth behaviour of a strain is known, as in the example above, OCQ and COQ can be used as simple triggers, or additional parameters to CER/OUR based control strategies in cases where these are not sensitive enough.

\section{Conclusions}

The results of this study show that the importance of the proportion of $\mathrm{O}_{2}$ and $\mathrm{CO}_{2}$ for secondary metabolite production might have been underestimated or even neglected, at least for bacteria in the genus Chondromyces. Preliminary results with bacteria from the genus Sorangium show that these findings can be expanded to this bacterial group as well (data not shown) and it is possible that the productivity of other microorganisms will benefit also through tight control of the gaseous environment. With 


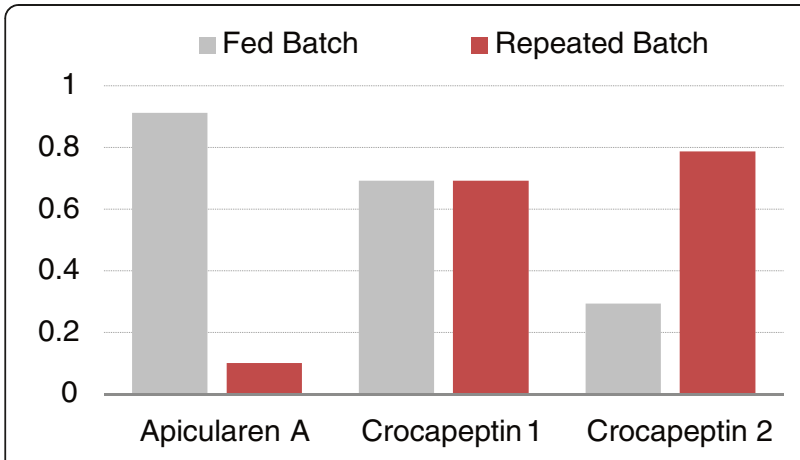

Figure 10 Comparison of the relative productivity of two substance groups produced in a repeated batch with subsequent capturing and batch with direct capture cultivation. The graphs represent relative peak areas in comparison to sulfadimethoxine as internal standard. For apicularen A, batch cultures are clearly superior. For crocapeptins results are comparable for one derivative and better for another derivative when metabolites are captured subsequently.

the method for $\mathrm{CO}_{2}$ and $\mathrm{O}_{2}$ maintenance described in this study, operators will have a powerful tool to investigate their influence with a relative simple instrumental setup. Furthermore, measurement of the off-gas allows by using the same principles used for controlling of the gaseous environment simple observation and control of bioprocesses with very few experiments and lack of detailed knowledge about media composition and intracellular biochemical processes by simply using very sensitive signals for respiratory activity.

\section{Methods}

Media and supplements

For cultivation of the Chondromyces strains, VY/2 media was used $\left(5 \mathrm{~g} / \mathrm{l}\right.$ baker's yeast, $1 \mathrm{~g} / \mathrm{l} \mathrm{CaCl}_{2} \mathrm{x}$ $2 \mathrm{H}_{2} \mathrm{O}, 100 \mu \mathrm{l} / \mathrm{l}$ vitamin solution, $2 \mathrm{ml} / \mathrm{l}$ trace element solution), cultivation of Saccharomyces cerevisiae was carried out in M9-minimal media $\left(6.78 \mathrm{~g} / 1 \mathrm{Na}_{2} \mathrm{HPO}_{4}\right.$

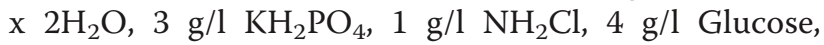
$2 \mathrm{ml} / \mathrm{l}$ of a $1 \mathrm{M} \mathrm{MgSO}_{4}$ solution, $100 \mu \mathrm{l} / \mathrm{l}$ of a $1 \mathrm{M}$ $\mathrm{CaCl}_{2}$ solution, $2 \mathrm{ml} / \mathrm{l}$ trace element solution). Trace element solution $\left(40 \mathrm{mg} / \mathrm{l} \mathrm{ZnCl}, 200 \mathrm{mg} / \mathrm{FeCl}_{3} \mathrm{x}\right.$ $6 \mathrm{H}_{2} \mathrm{O}, 10 \mathrm{mg} / \mathrm{l} \mathrm{CuCl}_{2} \times 2 \mathrm{H}_{2} \mathrm{O}, 10 \mathrm{mg} / \mathrm{l} \mathrm{MnCl}_{2} \times$ $4 \mathrm{H}_{2} \mathrm{O}, 10 \mathrm{mg} / \mathrm{l} \mathrm{Na}_{2} \mathrm{~B}_{4} \mathrm{O}_{7}$ x $10 \mathrm{H}_{2} \mathrm{O}, 10 \mathrm{mg} / \mathrm{l}\left(\mathrm{NH}_{4}\right)$ $6 \mathrm{Mo}_{7} \mathrm{O}_{24} \times 4 \mathrm{H}_{2} \mathrm{O}$ ). Vitamin solution $10 \mathrm{ml}(4 \mathrm{mg}$ Biotin, $64 \mathrm{mg}$ Na-pantothenat, $64 \mathrm{mg}$ nicotinamide, $64 \mathrm{mg}$ pyridoxal- $\mathrm{HCl}, 14 \mathrm{mg}$-amino benzoic acid, $14 \mathrm{mg}$ cobalamine).

\section{Cultivation of microorganisms}

Cultivation of Chondromyces strains was performed in repeated batch mode at $30{ }^{\circ} \mathrm{C}$. Cells clumps were sedimented and depleted medium was replaced twice daily with fresh medium. A repetitive growth pattern, where biomass remains comparable in each cultivation cycle was reached after a few days. This result in a typical growth pattern with high oxygen requirement at the beginning of the cultivation cycle and decreasing requirement when nutrients are depleted as well as identical base, acid and oxygen consumption patterns indicating that comparable batch conditions are reached. Investigations were performed when this stage was reached. The testing conditions were maintained for one cultivation cycle before the measurement cycle. To maintain comparable conditions, the cultivation vessel was equipped in the same manner with a baffle and electrodes on the same position for every run. The filling volume of a 21 vessel was 1.21 the remaining volume was used as headspace. $200 \mathrm{ml}$ cell clump volume remained in the reactor when media was exchanged. Cultivation of Saccharomyces cerevisiae was performed at $30{ }^{\circ} \mathrm{C}$ in minimal medium.

Two methods for maintenance of $\mathrm{pO}_{2}$ have been used and are indicated in the text. The first one achieves maintenance of $\mathrm{pO}_{2}$ by keeping the stirring rate at a constant level and changing the flow rate. The other method uses a constant flow rate and adapted stirrer speed for maintenance of $\mathrm{pO}_{2}$.

Relevant parameters were set under PI control using the following settings:

Stirrer : $\min 0, \max 800 ;$ P 0.2, I 0.2

Flow : $\min 0, \max 1.5 ; \mathrm{P} 0.7$, I 0.2

\section{Signal averaging}

To smooth the signals the average of added signals from three minutes sampled every ten seconds was taken.

\section{Equipment and calibration}

A Labfors 3 bioreactor microbial version (Infors Switzerland) was equipped with a 21 vessel and Iris 5.2 for process control. $\mathrm{O}_{2}$ in the media was measured with a polarographic electrode (Mettler Toledo Switzerland) calibrated using two-point calibration with compressed air and nitrogen gas. $\mathrm{pH}$ was measured with an electrode (Mettler Toledo Switzerland) calibrated at pH 7.00 and 4.01. The off-gas analysis system consisted of a zirconium dioxide $\mathrm{O}_{2}$ sensor and an infrared $\mathrm{CO}_{2}$ sensor (Bluesens Germany). The sensors were calibrated for $30 \mathrm{~min}$ with ambient air before connecting them to the exhaust gas stream.

\section{HPLC/MS measurements}

All measurements were performed on a Dionex Ultimate 3000 RSLC system using a Waters BEH C18, $100 \mathrm{x}$ $2.1 \mathrm{~mm}, 1.7 \mu \mathrm{m}$ dp column. Separation of $5 \mu \mathrm{l}$ sample with Sulfadimethoxine as internal standard was achieved by a linear gradient with (A) $\mathrm{H}_{2} \mathrm{O}+0.1 \%$ Formic acid (FA) to (B) Acetonitrile $+0.1 \%$ FA at a flow rate of $600 \mu \mathrm{l} / \mathrm{min}$ and $45{ }^{\circ} \mathrm{C}$. The gradient was initiated by a $0.5 \mathrm{~min}$ isocratic 
step at $5 \% \mathrm{~B}$, followed by an increase to $95 \% \mathrm{~B}$ in $18 \mathrm{~min}$ to end up with a 2 min step at $95 \% \mathrm{~B}$. The LC flow was split to $75 \mu \mathrm{l} / \mathrm{min}$ before entering the maXis $4 \mathrm{Ghr}$-ToF mass spectrometer (Bruker Daltonics, Bremen, Germany) using the standard ESI source. Mass spectra were acquired in centroid mode ranging from $150-2000 \mathrm{~m} / \mathrm{z}$ at $2 \mathrm{~Hz}$ scan speed.

\section{Determination of differences in productivity}

Metabolites were captured with XAD16 by incubating supernatant with resin for $1 \mathrm{~h}$ and subsequent extraction with $200 \mathrm{ml}$ methanol. The extracts of the different cultivations were weighed and compared by adjusting concentration with methanol. Sulfadimethoxine was used as internal standard at a concentration of $6.75 \mathrm{mg} / \mathrm{l}$. For comparison, twelve target compounds (TC) were chosen. The internal standard (IS) was to quantify the relative concentration of the twelve TCs in the six extracts by comparing the peak areas of the extracted ion chromatograms (EIC). To quantify the influence on overall productivity, the peak area of the TC is divided by the peak area of the IS. It is not possible to quantify the exact yield in $\mathrm{mg} / \mathrm{ml}$, but the overall differences in amount of the investigated substances in the six extracts can be calculated. The extract yield from the standard cultivation was used to calculate relative yield of the other extracts and TC/IS. An estimation of the influence of gaseous composition on overall productivity can then be made. For comparison of apicularens and crocapeptins, productivity concentration of the extract was adjusted and peak areas were compared.

\section{Determination of $\mathbf{k}_{\mathbf{l}} \mathbf{a}$}

The dependency of $k_{1} a$ on stirrer speed and flow was determined with the dynamic method without oxygen consumer. The bioreactor was filled to the cultivation level with water and oxygen was stripped before every measurement cycle with nitrogen gas. For determination of the influence on $\mathrm{k}_{\mathrm{l}} \mathrm{a}$ by bottom sparging a defined stirring speed and flow rate was adjusted for every cycle. For investigation of the influence of headspace aeration only a defined stirring rate was adjusted and a permanent exchange of headspace volume with air at $0.5 \mathrm{l} / \mathrm{min}$ was carried out. The maximum dissolved concentration of $\mathrm{O}_{2}$ at $30{ }^{\circ} \mathrm{C}$ was calculated to be $7.083 \mathrm{mg} / \mathrm{l}$ corresponding to the measured $\mathrm{pO}_{2}$ of $100 \%$. The increase between 1-2.5 mg/l was linear at all conditions therefore $\mathrm{k}_{\mathrm{l}} \mathrm{a}$ could be calculated by the following equation:

$$
k_{l} a=\frac{\ln \left(\frac{7.083 \frac{m g}{l}-1 \frac{m g}{l}}{7.083 \frac{m g}{l}-2.5 \frac{m g}{l}}\right)}{t_{2.5}-t_{1.0}}
$$

where $t_{1.0}$ is the time point when $1 \mathrm{mg} / \mathrm{l}$ oxygen saturation is reached and $t_{2.5}$ when $2.5 \mathrm{mg} / \mathrm{l}$ is reached

\section{Competing interests}

The authors declare that they have no competing interests.

\section{Acknowledgements}

We thank Prof. Dr.-Ing. Richard Biener and M. Sc. Janet Lei for careful proofreading of the manuscript. Financial support by the Bundesministerium für Bildung und Forschung and by the Deutsche Forschungsgemeinschaft is acknowledged.

\section{Authors' contributions}

SH designed the experiments, carried out the studies, evaluated the data and wrote the manuscript. RM supervised the study and wrote the manuscript. All authors read and approved the final manuscript.

Received: 8 March 2012 Accepted: 9 May 2012

Published: 9 May 2012

\section{References}

1. Harvey LA: Natural products in drug discovery. Drug Discovery Today 2008, 13(Issues 19-20):894-901.

2. Spizek J, Novotna J, Rezanka T, Demain LA: Do we need new antibiotics? The search for new targets. Journal of Industrial Microbiology and Biotechnology 2010, 37:1241-1248.

3. Hong J: Role of natural product diversity in chemical biology. Current Opinion in Chemical Biology 2011, 15(Issue 3):350-354

4. Wenzel SC, Müller R: The biosynthetic potential of myxobacteria and their impact on drug discovery. Current Opinion in Drug Discovery \& Development 2009, 12(2):220-230.

5. Reichenbach $\mathrm{H}$, Höfle G: Discovery and development of the epothilones-a novel class of antineoplastic drugs. Drugs $R \& D$ 2008, 9(1):1-10.

6. Garcia RO, Krug D, Müller R: Discovering natural products from myxobacteria with emphasis on rare producer strains in combination with improved analytical methods. In Methods in Enzymology 2009, 458:59-91.

7. Kunze B, Jansen R, Sasse F, Höfle G, Reichenbach H: Chondramides A-D, New Antifungal and Cytostatic Depsipeptides from Chondromyces crocatus (Myxobacteria). The Journal of Antibiotics 1995, 48(11):1262-1266.

8. Kunze B, Jansen R, Sasse F, Höfle G, Reichenbach H: Apicularens A and B, New Cytostatic Macrolides from Chondromyces Species (Myxobacteria): Production, Physico-chemical and Biological Properties. The Journal of Antibiotics 1998, 51(12):1075-1080.

9. Gentzsch J, Hinkelmann B, Kaderali L, Irschik H, Jansen R, Sasse F, Frank R, Pietschmann T: Hepatitis $C$ virus complete life cycle screen for identification of small molecules with pro-or antiviral activity. Antiviral Research 2011, 89:136-148.

10. Yegneswaran PK, Gray MR: Effect of Dissolved Oxygen Control on Growth and Antibiotic Production in Streptomyces clavuligerus Fermentations. Biotechnology Progress 1991, 7:246-250.

11. Liefke $E$, Kaiser D, Onken U: Growth and product formation of actinomycetes cultivated at increased total pressure and oxygen partial pressure. Applied Microbiology and Biotechnology 1990, 32:674-679.

12. Frykman SA, Tsuruta H, Starks CM, Regentin R, Carney JR, Licari P: Control of Secondary Metabolite Congener Distribution via Modulation of the Dissolved Oxygen Tension. Biotechnology Progress 2002, 18:913-920.

13. Jones PR, Greenfield PF: Effect of carbon dioxide on yeast growth and fermentation. Enzyme Microbial Technology 1982, 4:210-223.

14. Dixon NM, Kell DB: The inhibition by $\mathrm{CO}_{2}$ of the growth and metabolism of micro-organisms. Journal of Applied Bacteriology 1989, 67:109-136.

15. McIntire $\mathrm{M}, \mathrm{McNeil} B$ : Effects of Elevated Disoolved $\mathrm{CO}_{2}$ Levels on Batch and Continuous Cultures of Aspergillus niger A60: an Evaluation of Experimental Methods. Applied and Environmental Microbiology 1997, 63 (11):4171-4177.

16. Dahod SK: Dissolved Carbon Dioxide Measurement and its Correlation with Operating Parameters in Fermentation Processes. Biotechnology Progress 1993, 9:655-660

17. Shang L, Jiang M, Ryu CH, Chang HN, Cho SH, Lee JW: Inhibitory Effect of Carbon Dioxide on the Fed-Batch Culture of Ralstonia eutropha: Evaluation by $\mathrm{CO}_{2}$ Pulse Injection and Autogenous $\mathrm{CO}_{2}$ Methods. Biotechnology and Bioengineering 2003, 83(3):312-320.

doi:10.1186/1475-2859-11-59

Cite this article as: Hüttel and Müller: Methods to optimize myxobacterial fermentations using off-gas analysis. Microbial Cell Factories 2012 11:59. 